\title{
A escrita desarrumada de Mia Couto: diálogos com a obra rosiana
}

Avani Souza Silva ${ }^{1}$

RESUMO: Em sua poética, Mia Couto promove uma ruptura na língua, na sua feição europeia, aproximando-a da oralidade de seu país. Guimarães Rosa opera virtualidades na língua, dinamizando-a para alcançar a máxima expressividade, consoante seu projeto estético-literário. Pontos de convergência dessas fraturas na língua, como diria Mia Couto, são enfocados neste texto.

ABSTRACT: In his poetics, Mia Couto promotes a rupture in language, in its European feature, approaching it to orality of his country. Guimarães Rosa produces virtualities in language, boosting it to reach the maximum expressiveness, consonant with his aesthetic literary project. Points of convergence of these disruptions in the language, according to Mia Couto, are focused on this text.

PALAVRAS-CHAVES: Oralidade; Paródia; Neologismos; Mia Couto; Guimarães Rosa.

KEYWORDS: Orality; Parody; Neologisms; Mia Couto; Guimarães Rosa.

Há, entre os textos de Mia Couto e de Guimarães Rosa, muitos diálogos, seja na estrutura, nos temas, no espaço, nas personagens, nas vozes, mas principalmente, e é o que nos interessa neste momento, na maneira com que os escritores trazem a oralidade para dentro do discurso literário.

O escritor moçambicano discorre sobre a gênese de sua obra em diversas entrevistas. Selecionamos aquela concedida a Rita Chaves e Omar Ribeiro Thomaz ${ }^{2}$, na qual o escritor aborda a reconstrução linguística de seus textos, ou como diz, de sua escrita desarrumada, expressão que dá título à entrevista. Sobre a forte presença da oralidade em sua obra, primeiramente ele declara que a oralidade o invade e

\footnotetext{
1 Doutoranda na área de Estudos Comparados de Literaturas de Língua Portuguesa da FFLCH/USP.

2 Entrevista publicada no jornal Folha de S. Paulo, no caderno Mais, edição de 23.09.1998.
} 
desarruma a escrita em tudo até o limite. O escritor esclarece que o desvio linguístico com relação à norma portuguesa faz parte da oralidade de seu país, de onde ele nutre seu universo ficcional. Ele se apercebe desses desvios como qualquer coisa que pode introduzir beleza ou que interrogue aquilo que é familiar no universo moçambicano. Uma outra função dada ao uso da linguagem oral é a de operar em nível real, mostrando como as pessoas estão se expressando. Há, portanto, para ele, uma fratura com relação à língua oficial que tem de ser descoberta, tem de ser revelada, e os desvios linguísticos são sinais que podem mostrar isso.

Essa linguagem "despedaçada" espelha a dificuldade que as pessoas têm, quanto ao português padrão, para expressarem o seu mundo. O escritor conclui, na referida entrevista: "Elas estão lidando com uma língua que é de outro mundo, com outra lógica, e elas têm que despedaçá-la para que a língua possa ser sua" (CHAVES, THOMAZ, 1998). Mia Couto se refere à apropriação da língua do colonizador com as virtualidades da língua do colonizado. Ele opera, pois, neste interstício, imprimindo sua marca poética.

Russel Hamilton lembra que "a desintegração linguística é tanto um desafio à língua imposta quanto uma apropriação dela" (HAMILTON, 1984). Relata que para José Craveirinha, por exemplo, "desintegrar o discurso poético comedido e ir além dos limites convencionais da linguagem (...) eram em si atos revolucionários", instrumento de luta anticolonialista de que se serviu em sua poética, principalmente ao introduzir o ronga, língua do grupo banto, de que também era falante. Luandino Vieira, em Angola, inaugura uma revolução na linguagem ao se apropriar dela como instrumento de libertação do opressor, e promover uma verdadeira africanização ou quimbundização do idioma.

A língua portuguesa, com feição africana, como projeto de identidade nacional é instrumento de afirmação em diversos escritores e aqui, em particular, em Mia Couto. Citamos os casos de Luis Bernardo Howana, José Craveirinha, Paulina Chiziane etc., como nos 
lembra Russel Hamilton (1984). Moçambique está localizada na zona linguística da família das línguas chamadas banto e o Português, escolhido como língua oficial do país após a Independência de 1975, é falado por menos de 30\% da população, constituindo a segunda língua (L2) para a quase totalidade dos falantes moçambicanos, como afirma Perpétua Gonçalves (1996). Por ser a segunda língua para a maior parte de seus locutores, está, por essa razão, em situação constante de contato de línguas. Segundo Gonçalves, em Moçambique não atinge 5\% o número de falantes que tem o Português como lingua materna, enquanto mais de $95 \%$ da população têm como língua materna uma lingua da família banto, dentre as quais as que têm a mais longa tradição urbana em Maputo são o ronga e o changane. (GONÇALVES, 1996)

Notamos que a política de assimilação levada a efeito pelo colonialismo português massacrava a população local tentando civilizála, impondo-lhe os valores portugueses para que essa população pensasse e agisse não como negros autóctones, mas como arremedo de homem branco, o assimilado ${ }^{3}$. A escola dirigida por portugueses em Moçambique ensinava a lingua do colonizador, proibindo as línguas nacionais. E este também foi um fator muito determinante nas alterações do português-padrão, porque era uma lingua imposta cujo curso tentava asfixiar as linguas nativas para melhor dominar ideologicamente seus falantes, ocupando o seu lugar nas comunicações cotidianas.

A mesma lingua que serviu para dominar passa a ser um instrumento de libertação e afirmação, quando desenha em si uma feição africana (CHAVES, 2004). Mia Couto imprime uma marca africana no idioma: expressões de origem banto, incorporação de neologismos (processos de aglutinação e afixação, amálgamas,

3 Como relata Russel Hamilton, segundo a lei da assimilação, o africano para ser reconhecido oficialmente como civilizado tinha que se submeter a um processo de europeização. Para ser considerado um assimilado ele via-se obrigado a abandonar os usos e costumes tradicionais, adotar a religião cristã, falar e ser alfabetizado em português e portar-se sob as normas do sistema econômico imposto pelos colonizadores. (CAMPOS, 2000, p. 2000, p. 11-35). 
nominalizações etc.), veiculação de provérbios nas línguas nacionais, incorporação do português desviante, paródia ou inversão de ditos portugueses.

Segundo Ana Mafalda Leite, é no português desviante (modalidade que se contrapõe ao português culto de estrato europeu) que Mia Couto vai imprimir sua marca poética. (LEITE, 1998). Também para Perpétua Gonçalves, Mia Couto parece sentir-se libertado do jugo das regras da gramática do português padrão europeu, e o seu processo inovador inspira-se no contexto linguístico moçambicano (GONÇALVES, 1996, p.23). Lembra, entretanto, que as inovações lexicais do escritor são formadas com base em material pré-existente no Português, sendo irrelevantes no seu discurso literário e que, além disso, os empréstimos são pouco frequentes e, quando ocorrem, são explicados em notas de rodapé, ou em glossário (GONÇALVES, 2000, p. 223).

No início da década de 1980, Michel Laban ${ }^{4}$ já estudava as particularidades do português de Moçambique através da literatura, e partir dos anos 90 aprofundou suas pesquisas, percebendo que os escritores moçambicanos que afrontavam a norma linguística de referência, a de Lisboa, eram aqueles que se identificavam com as questões nacionalistas do país, e tinham o objetivo de denunciar a situação colonial, utilizando eventualmente a língua do povo. Segundo o autor, essa opção nacionalista está presente emblematicamente em Nós matamos o cão tinhoso, de Luís Bernardo Honwana, publicado em 1964, e na poesia de José Craveirinha, por vezes enraizada num léxico local, que é a língua ronga, do grupo banto, o grupo de língua nacional majoritariamente falado em toda a África subsaariana. Para Craveirinha, criar um viés nitidamente moçambicano na língua do colonizador era uma arma revolucionária.

Durante o período colonial, essa postura nacionalista dos escritores tinha o propósito de proclamar a autonomia da língua

\footnotetext{
${ }^{4}$ LABAN, Michel. Reflexões sobre a elaboração de um inventário das particularidades do português de Moçambique através da literatura. Disponível no
} http://www.geocities.com/ail_br/reflexoessobreelaboracaodeinventario.htm 
portuguesa falada em Moçambique e, ao mesmo tempo, a autonomia da cultura e das aspirações sociopoliticas do povo. Esse foco, porém, muda com a vitória da Guerra de Independência. O estado escolheu a língua portuguesa como a língua oficial do país, e, sendo assim, os escritores moçambicanos ao recorrerem às particularidades da língua popular imprimiam a esse ato um novo significado: era um meio de mostrar o sofrimento do povo (principalmente durante o conflito armado que se seguiu à Independência), sobretudo, daquele povo que vivia à margem social, e nas áreas rurais, distantes de onde se falava o português padrão.

Russel Hamilton lembra que os primeiros movimentos literários nativistas que nasceram em Angola e Moçambique coincidiram, não por acaso, com o nascer dos movimentos de libertação, nos anos 50: "Os intelectuais eram dos movimentos. E muitas das obras literárias produzidas nesse período se caracterizaram pelo protesto social, reivindicação cultural e uma crescente combatividade" (2000, p. 11-35). Portanto, a contaminação da língua padrão portuguesa com as cores nacionais veio na esteira dos movimentos de libertação nacional, como proposta política de emancipação e de resgate da nacionalidade violentada pela política colonial. É nessa visada que se enquadram os experimentos linguísticos de Mia Couto.

Já no contexto brasileiro, a revitalização da língua e a sua reconfiguração, como fez Guimarães Rosa, fazem parte de um projeto estético do escritor para obter a máxima expressividade, atingindo o ápice no conto "Meu tio, o Iauaratê", em que há uma verdadeira engenharia linguística. Para Walnice Galvão, há, neste conto, três canais de comunicação que formam uma linguagem original, permitindo ao escritor mineiro realizar a identificação sonora e semântica entre o homem e a onça: "o português, o tupi do índio mestiço protagonista do conto e as onomatopéias da onça" (GALVÃO, 2000, p. 64).

O processo de revitalização da língua, tanto em Guimarães Rosa, quanto em Mia Couto, insere-se na adoção de uma postura política por 
parte de ambos. Guimarães Rosa, afinado com as vanguardas europeias, tinha clareza no tocante à importância do fazer literário como construção, e a revitalização da língua portuguesa para ele era um instrumento de dignificação da literatura brasileira. Mia Couto, imbuído do sentido político-ideológico, em sintonia com os movimentos de libertação e com os escritores engajados de seu tempo, apropria-se literariamente da língua do colonizador como instrumento da nacionalidade, imprimindo-lhe as cores locais.

A obra de Guimarães Rosa e de Mia Couto enfocam as possibilidades de explorar as relações entre oralidade e escrita. No caso de Mia Couto, para indicarmos a presença da oralidade, em termos de construção linguística, teríamos de fazer uma pesquisa de campo em Moçambique ou recorrer a estudos do português oral do país, estudos esses a que não tivemos acesso. Desta forma, destacamos preliminarmente a oralidade pelo discurso do narrador: frases curtas, predominantemente de orações coordenadas, interpelações do interlocutor, interrogações retóricas, como no conto "Afinal Carlota Joaquina não chegou de voar", de Vozes anoitecidas, onde, aliás, emerge uma aproximação com o monodiálogo de Riobaldo.

No caso de Guimarães Rosa, notadamente em Sagarana e Grande sertão: veredas, além de a fala das personagens remeterem à oralidade do Norte de Minas, ele também utiliza a pontuação e outros sinais gráficos para representar a pronúncia e criar a ilusão de oralidade.

$\mathrm{Na}$ escrita de Mia Couto evidencia-se uma multiplicidade de neologismos, das mais variadas formações - "cristalinda, predispronto, animaldades, sozinhação, sobrancelhar, defuntar, desvoar, desouvir, bicego, vislembrança, milvagaroso, acontecências..." Essa multiplicidade de neologismos dialoga com a linguagem rosiana, que é pontuada de arcaísmos, estrangeirismos, neologismos vários, por derivação, aglutinação, afixação, amálgamas, nominalizações, diminutivos de verbos, de preposições - "acontecências, diligentil, beladormeceu, estremeceuzinha, desouvir, desviver, redondoso, 
reperfeito, sozinhidão, desalegria, descabisbaixo, desonçar, desdentadura, pensamor, milmente" — etc.

Destacamos alguns neologismos que se presentificam nas obras dos escritores, remetendo-nos de um para outro em diálogos. Substantivos tornam-se verbos ou advérbios, advérbios e pronomes indefinidos sofrem variações etc.:

Falava devagarmente. (Vozes anoitecidas, p.123)

Disse adeus para todos, sempremente. (Grande sertão: veredas, p. 531)

Talmente eu podia lá ir. (Grande sertão: veredas, p. 490)

Cada qual, conforme. Cadaqualmente. (Vozes anoitecidas, p.110)

$\mathrm{Na}$ obra do escritor moçambicano, além do surgimento de expressões das línguas do grupo banto, há aquelas criadas pelo autor através de adaptações de termos bantos às regras fonológicas e/ou morfológicas do português, como o exemplo apontado por Gilberto Matusse (1988, p. 96): "Só o vento cumpria função de enxada, kulimando areias", de Cada homem é uma raça (p. 138).

Recorrer a outras linguas para criar novas expressões também é um procedimento do escritor mineiro. Citamos como exemplo o nome da personagem Moimechego, do conto "Cara-de-Bronze" (No Uburuquaquá, no Pinhém), que é formado por uma variante do pronome pessoal "eu" em diversos idiomas (moi, me, ich, ego), conforme explicações dadas pelo escritor mineiro a seu tradutor italiano, Edoardo Bizarri. Outro exemplo, tirado do conto "Darandina", de Primeiras estórias, é a expressão paraláparacáparlar, um sintagma a evidenciar uma troca reiterada de informações ou diálogo entre duas pessoas. Ou ainda, do mesmo conto, o léxico voxpopular.

Tanto na obra de Guimarães Rosa quanto na de Mia Couto a linguagem utilizada omite a conjunção integrante "que" nas orações substantivas. A omissão dos conectivos "como se" e "se" antes do subjuntivo, que se observa na obra de Guimarães Rosa, é um fenômeno da oralidade no norte de Minas, como constatou Teresinha Ward (1984) em pesquisa de campo. Acreditamos que idêntico fenômeno também 
seja da oralidade em Moçambique, também utilizado por Mia Couto. Vejamos os exemplos:

Assim, parecesse que tinha vergonha, de estarem comprando aquele arroz, o senhor veja. (Grande sertão: veredas, p. 90)

E os dois pelo caminhinho não deixavam nenhuma pegada, fossem pisando não a areia mas o céu. (Estórias abensonhadas, p.171)

Presentes nos textos de ambos os escritores a inversão de elementos na frase:

(...) Mas nada não falou. (Vozes anoitecidas, p. 51)

Nosso pai nada não dizia. (Primeiras estórias, p. 32)

A realização de jogos fônicos com assonâncias em ritmo binário é outro recurso estilístico que se revela na construção linguística dos escritores, estabelecendo diálogos entre os textos:

A praça reclamava, clamava. (Primeiras estórias, p.130)

Mas Dulcineusa não cede nem concede. (Um rio chamado tempo, uma casa chamada Terra, p. 33)

Psiu, porém, quem, assado e assim, a mundos e resmungos (...). (Primeiras estórias, p. 126)

Contudo, os cantares de encanto, os pios e rodopios (...). (Cronicando, p.125)

Presentes nas narrativas de Guimarães Rosa há neologismos do campo semântico dos animais: raposice, gateza, encachorrar etc. Mia Couto também constrói muitas palavras desse campo semântico, incrementando sua linguagem: tartarugar, crocodilejar, enjiboiar, caranguejar, encachorrar, peixar, animalar etc.

Ambos os escritores subvertem expressões cristalizadas. Para Mia Couto é uma marca de estilo, dentro do projeto de identidade nacional e 
de apropriação da língua do colonizador. Para Guimarães Rosa é a dinamização da língua, a fuga do lugar comum:

Um leão ruge a plenos trovões. (Ave palavra, p. 67)

Ou era apenas conversa a crédito? (Vinte e zinco, p.52)

Disse isso baixo e mau-som. (Primeiras estórias, p.31)

Me faço desentender? (A varanda do frangipani, p. 131)

Era o impasse da mágica. (Tutaméia, p.148)

Ressaltamos o papel de transmissor de regras do bom viver desempenhado pelos provérbios nas narrativas orais. De acordo com Walter Benjamin, a verdadeira narrativa tem em si, às vezes de forma latente, uma dimensão utilitária que aponta para o papel do conselheiro que o narrador tradicional desempenha:

Essa utilidade pode consistir seja num ensinamento moral, seja numa sugestão prática, seja num provérbio ou numa norma de vida - de qualquer maneira, o narrador é um homem que sabe dar conselhos. (BENJAMIN, 1986, p. 200)

Ainda segundo Benjamin, os provérbios "são ruinas de antigas narrativas, nas quais a moral da história abraça um acontecimento, como a hera abraça o muro" (1986, p. 201).

Mia Couto resgata os ditos populares moçambicanos e os inclui em sua narrativa na forma em que são veiculados. No entanto, quando ele recorre aos ditos portugueses, que também fazem parte da oralidade de seu país, e aí reside a cor política do escritor e seu senso de humor, ele os modifica ou subverte. Guimarães Rosa também faz paródia de provérbios, ditos e expressões, resvalando em humor.

Cão que ladra não é mudo. (Primeiras Estórias, p.129)

Cão que ladra é porque tem medo de ser mordido. (A chuva pasmada, p. 5)

Vá-se a camisa que não o dela dentro. (Tutaméia, p.158)

A aldeia estaria metida em vara de sete camisas. (Contos do nascer da terra, p. 14)

Todo soldado tem um pouquinho de chumbo. (Tutaméia, p.158) Mais vale é nenhum pássaro na mão. Mais vale é ver a passarada desfraldando asas na paisagem. (Vozes anoitecidas, p.184) 
Todo mundo tem onde cair morto. (Tutaméia, p. 128)

Siga-se o improvérbio: dá-se o braço e logo querem a mão. (Cronicando, p. 215)

O feio está ficando coisa. (Primeiras Estórias, p. 129)

Se os provérbios têm a finalidade de trazer a cultura popular de estrato oral para o centro do discurso literário e destinam-se a perpetuar a memória, papel igualmente importante neste processo, desempenham as cantigas populares, pois nas sociedades em que predomina a oralidade os cânticos são importantes, porque também revelam ensinamentos, conselhos, brincadeiras. A produção literária de Mia Couto ressente-se, todavia, da presença desses cantos. Em Guimarães Rosa, ao contrário, sua obra é pontuada de cantigas, sendo a mais famosa a "Canção de Siruiz", em Grande sertão: veredas.

Pudemos observar um diálogo nas linguagens criativas de Guimarães Rosa e de Mia Couto: ambos encenam a oralidade, resgatam a cultura popular e revitalizam a língua. Entendemos, porém, que o diálogo mais fecundo entre os dois escritores, a par do tempo e do espaço de cada qual, é que ambos são grandes contadores de estórias.

\section{Referências bibliográficas}

Couto, Mia. Vozes anoitecidas. Lisboa: Caminho, 1987. . Cronicando. Lisboa: Caminho, 1991.

_ _ Estórias abensonhadas. Lisboa: Caminho, 1994. A varanda do Frangipani. Lisboa: Caminho, 1996.

_. Contos do nascer da terra. Lisboa: Caminho, 1997. Um rio chamado tempo, uma casa chamada terra. Lisboa: Caminho, 2001.

A chuva pasmada. Lisboa: Caminho, 2004.

BENJAMIN, Walter. "O narrador: considerações sobre a obra de Nicolai Leskov" In: Magia e técnica, arte e politica: ensaios sobre literatura e história da cultura. São Paulo: Brasiliense, 1986.

CHAVES, Rita. "O passado presente na literatura africana" In Via Atlântica. São Paulo, Centro de Estudos Portugueses / FFLCH / USP, n.7, 2004.

GALVÃO, Walnice Nogueira. Guimarães Rosa. São Paulo: Publifolha, 2000. 
GONÇALVES, Perpétua. Português em Moçambique: uma variedade em formação. Maputo: Universidade Eduardo Mondlane, 1996.

HAMILTON, Russel. Literatura africana literatura necessária. Lisboa: Edições 70, 1984.

"Introdução" In: CAMPOS, Maria do Carmo Sepúlveda et al. África e Brasil: letras e laços. Rio de Janeiro: Atlântica, 2000, p.11-35.

MATUSSE, Gilberto. A construção da imagem de moçambicanidade em José Craveirinha, Mia Couto e Ungulani Ba Ka Khosa. Maputo: Universidade Eduardo Mondlane, 1988.

ROSA, João Guimarães. Tutaméia: terceiras estórias. Rio de Janeiro: Nova Fronteira, 1985.

Ave palavra. Rio de Janeiro: Nova Fronteira, 1985.

_. Grande sertão: veredas. Rio de Janeiro: Nova Fronteira, 1986. Primeiras estórias. Rio de Janeiro: Nova Fronteira, 1986.

WARD, Teresinha Souto. O discurso oral em Grande sertão: veredas. São Paulo / Rio de Janeiro: Duas Cidades / INL / Fundação Nacional Pró-Memória, 1984. 